\title{
Computers lose on the swings and the roundabouts
}

Tight university research budgets are contributing to a shortage of computer science graduates in the US. But concern is also growing about the social effects of automation.

\section{David Dickson reports}

Next Saturday, half a million members of the Communication Workers of America are holding a national "Job Pressures Day" to protest at the way in which automation is dehumanising working conditions. No one will stop work, the intention is to draw public attention to the issue through informational picketing and other activities under the general slogan "we are people not machines".

The action is claimed to be unprecedented for a major US union, most of which keep strictly to the conventional issues of wages and working hours. But it heralds a trend within the US labour movement which, fuelled by evidence that automation may finally be resulting in the unemployment previously predicted but unrealised, promises to grow substantially over the next few years.

Even without these new complaints about working conditions, the manpower implications of computers-a subject of hot debate in the late 1950 s and 1960s, but one that subsided as economic prosperity cushioned any significant impact-are once again causing serious concern in policymaking circles.

On the one hand, support is declining for experimental computer science in US universities, and attracting good staff and students has become a problem. As a result, there are not enough qualified graduates for industry's needs. Many computer companies now face major difficulties in recruiting staff and have expressed their concern to the Office of Science and Technology Policy.

A report published last month by an advisory committee to the National Science Foundation says that as a result of funding difficulties, computer science research is now in a "critical" situation. University programmes are declining, just when the size and quality of research and training should be increasing to meet industry's needs. The report points out that, with obsolete equipment and inadequate finance, many of the best staff are now being recruited away from universities, whose research laboratories were originally responsible for such central innovations as time-sharing techniques, virtual memory systems and file protection mechanisms.

A particular concern, the committee says, is the fall in the number of computer science doctorates in the past two years. "Because of its leverage in stimulating research, retaining faculty and capturing the interest of superior students, the most important requirement is the establishment and maintenance of outstanding university research facilities," it says. This could be achieved by injecting as little as $\$ 15$ million a year, based on five capital grants of $\$ 2$ million to separate institutions, plus running costs for each for the following five years. OSTP is now trying, with the support of industry, to persuade the Office of Management and Budget that this will be money well spent.

But while the management side of industry is complaining about a shortage of qualified recruits, labour is concerned about those who will lose their jobs as a result of automation. Until recently, the conventional wisdom was that unemployment was outweighed by the extra jobs created through increased prosperity. Now, with with a stagnant economy plus the rapid incursion of automation into previously untouched areas such as office work, there are doubts about this equation.

A typical survey carried out by the Society of Manufacturing Engineers predicted recently that $20 \%$ of the labour directly involved in the final assembly of automobiles will be replaced by machines-such as robot

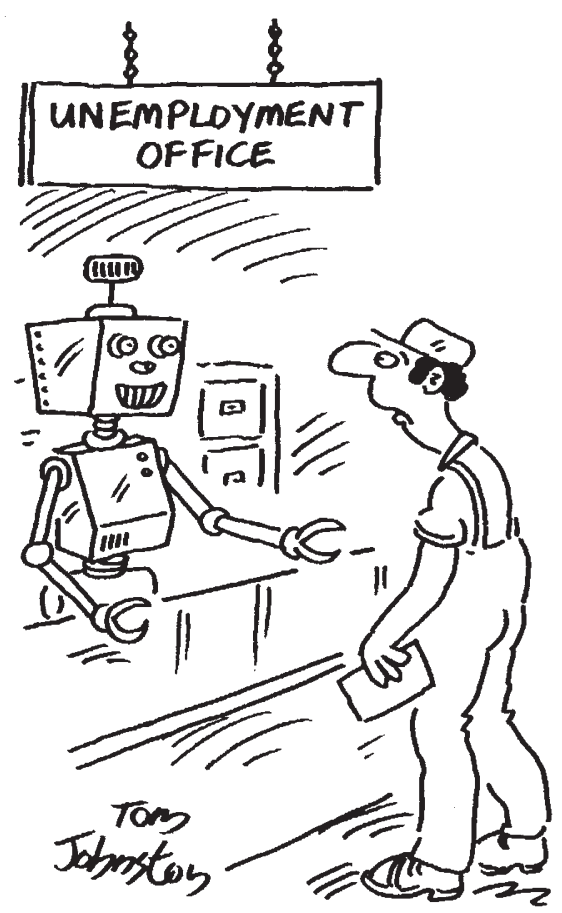

1995 .

Similarly, a Bureau of Labour Statistics report on telecommunications technology concludes that "the anticipated strong demand for communications will probably modify the adverse effects on employment, but can no longer offset them. As a result, employment is expected to decrease slowly into the mid-1980s, significantly altering job skills and occupational composition."

Such automation seems likely to result in a "substantial permanent sector of unemployment", as a result of society's inability to cope with the effects of new technology, predicts Robert T. Lund, a senior research associate at MIT's Centre for Policy Alternatives. Part of the problem, he suggests, is that the 1950 s automation scare which failed to materialise has led to a false sense of security.

Some indication of the size of the problem may be given when the Office of Technology Assessment produces the results of a survey it is conducting as part of a broader project on the social impact of data processing systems, with a view to seeing whether any Congressional action may be needed. "It is certainly an issue that deserves more attention than it has been getting," says Mr Stephen Doyle, group manager for telecommunications at OTA.

Meanwhile there is discontent among those who are at the receiving end of the new technology. A survey conducted by the University of Michigan has just reported that, for the first time, there was a decline in the national level of job satisfaction, as measured between 1973 and 1977. The survey of 1,515 workers found that $36 \%$ felt their skills were underused, and $32 \%$ that they were "overeducated". There was a "slight but significant" drop in overall job satisfaction.

The unions are already beginning to react, largely in response to rank-andfile pressure. In addition to next week's WA demonstration, members of the United Auto Workers made strong demands at a recent conference for tougher terms on retraining, monitoring technical change and giving early notice of automation plans.

Mr Glenn E. Watts, CWA president, goes further. In a recent article he said that his union believes major technological advances should be held in check until a human impact study has been made, just as environmental impact studies are carried out in other circumstances. "If some workers today are bored and alienated, the degrading of work itself must be recognised as part of the problem." 